\title{
Laryngeal Chondroma
}

\author{
A. K. Gupta, Assistant Professor, S. B. S. Mann, Professor \& Head, \\ Suresh C. Sharma, Additional Professor, K. K. Handa, Senior Resident \\ Post Graduate Institute of Medical Education \& Research, Chandigarh 160012, India.
}

Chondroma of thyroid cartilage is a rare condition. Two cases of laryngeal chondroma diagnosed clinically and confirmed histopathologically are presented. Surgical excision was undertaken in both the cases.

\section{Key Words}

Thyroid cartilage, cricoid cartilage.

\section{INTRODUCTION}

Laryngeal chondroma is a slow growing tumor which most frequently involve postero lateral plate of cricoid cartilage. The tumor most frequently arises from circoid cartilage $(70 \%)$ but may arise from thyroid cartilage $(20 \%)$ or from the body of arytenoid cartilage $(10 \%)$ ) (Contrell et al. 1980 and Huizengo et al. 1970). Singh et al. (1980) while presenting two cases of laryngeal cartilagenous tumors could find only 177 reported cases of laryngeal chondromas in English Literature. It is important to note that the published data also includes lesions of true vocal cords which usually represents metaplasia of the elastic connective tissue rather than true chondromas. Secondly, only the tumors arising from haline cartilage of the larynx are considered as true neoplasm rather than those arising from elastic cartilage. Thus the incidence of true laryngeal chondroma in real sense becomes much less than that reported in literature.

We are reporting two cases of laryngeal chondromas arising from thyroid cartilage.

\section{CASE REPORT I}

A 42 years male patient reported to the Deptt. of Otolaryngology and Head \& Neck Surgery at the
Post Graduate Institute of Medical Education \& Research, Chandigarh with complaints of progressive dyspnoea and cough of two years duration. To start with, the dyspnoea was on mild to moderate exertion but later it menifested even at rest. After one year, patient also noted a change in his voice. All bio-chemical and hematological investigations were normal. Indirect laryngoscopy revealed a smooth subglottic mass on right side. CT scan of the neck showed a contrast enhancing subglottic mass arising from the thyroid cartilage (Fig. $1+2$ ).

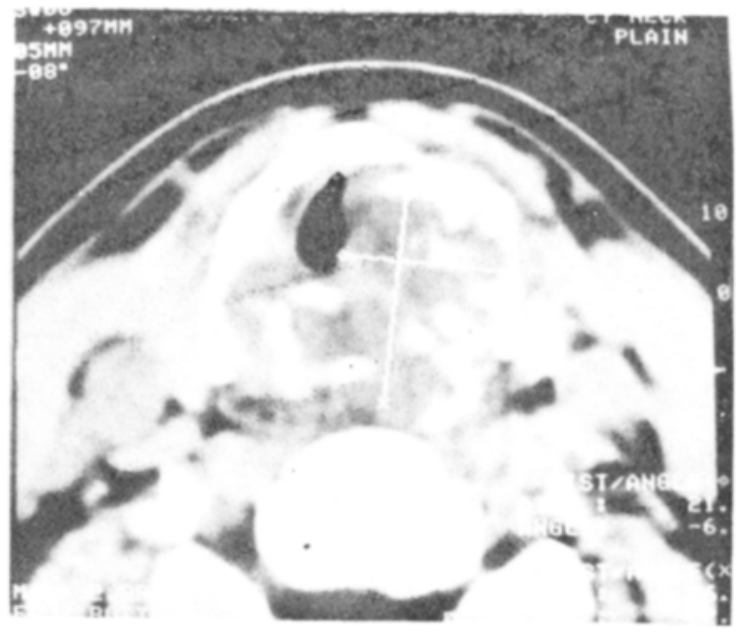

Fig.1:

CT Scan showing subglottic mass arising from thyroid cartilage

An x-ray of the chest was normal. Direct laryngoscopy showed a whitish smooth mucosa covered mass in subglottis which was firm in consistency, non-compressible and non pulsatile. An operative procedure was undertaken under general anaesthesia using endotracheal intubation. A transverse incision was made over 


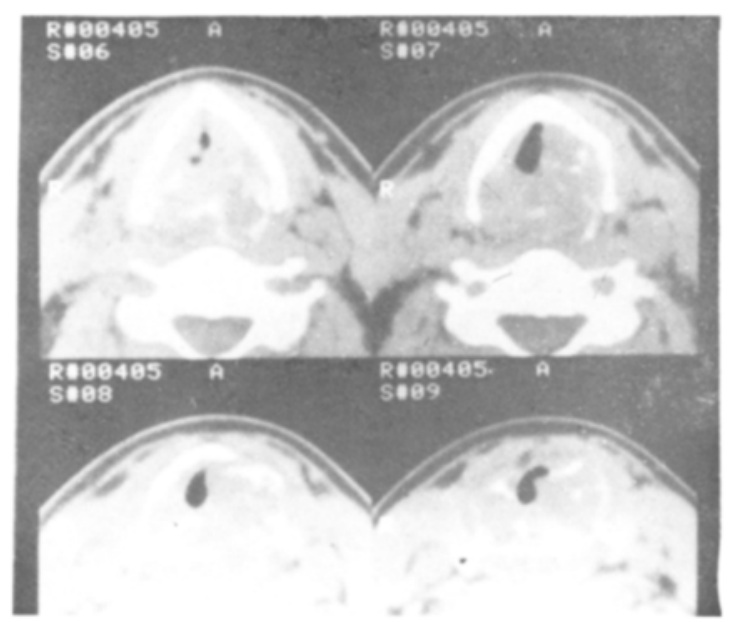

Fig. 2:

Subglottic mass with narrowing of glottic space

pomum adomi and dissection was carried out upto thyroid cartilage. Thyroid cartilage was split in the midline and a smooth, submucosal subglottic mass measuring $2 \mathrm{~cm} \times 1.5 \mathrm{~cm}$ invading posterior laminae of thyroid cartilage was excised. Post operative period was uneventful.

Decanulation was done 2 weeks following surgery and the patient was alright during follow-up.

\section{CASE REPORT II}

A male patient aged 30 years presented with history of change in voice of 2 years duration and breathing difficulty since 2 months. Tracheostomy and diagnostic endoscopy was done. Endoscopy review revealed a smooth mucosa covered globular mass in subglottis from which a biopsy was taken. Histopathological examination of biopsy specimen was chondroma. Patient was planned for surgical excision via laryngofissure approach. But the patient refused surgery and left against medical advice.

\section{DISCUSSION}

Laryngeal chondromas are slow growing tumors which clinically menifest as progressive dyspnoea, neck mass and dysphagia. Hoarseness of voice though present is usually a late presentation. These are usually seen between 4060 years of age with a male dominance in the ratio of $5: 1$.

Neel and Umni (1982) however observed that most of the patients present with a smooth mucosa covered rounded mass in subglottic region usually in posterolateral position. The mass is firm in consistency which makes the biopsy unrewarding in most of the cases. Thus radiological investigations become more diagnostic because they delineate the extent and site of origin of the tumor more clearly.

Histologically, it is very difficult to differentiate between chondroma and low grade chondrosarcoma. Chondromas contain extensive perivascular woven bone with a marrow. Focal enchondral ossification has also been seen at the margins of tumor. A few chondrocytes with small

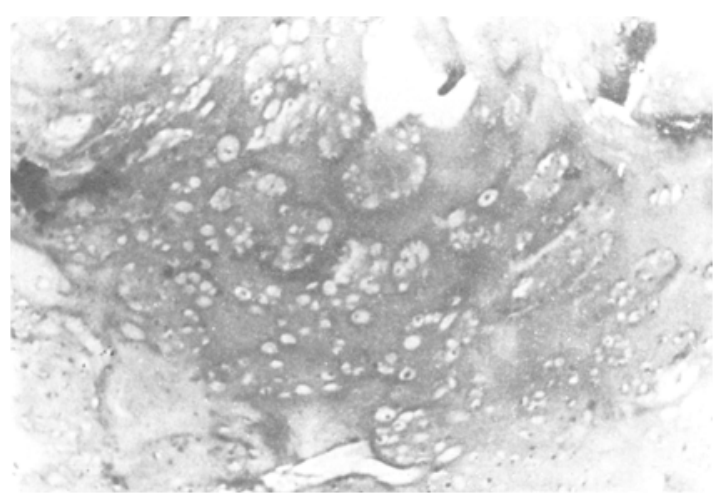

Fig.3:

HAE $\times 30$ showing chondrocytes

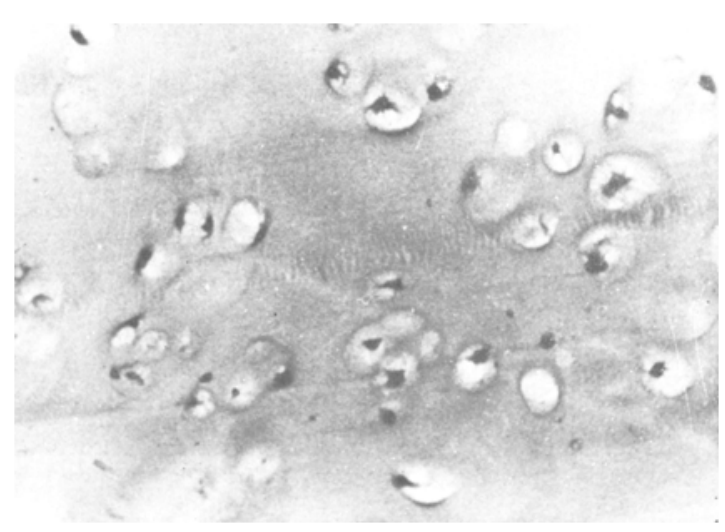

Fig.4:

H\&E $\times 600$ showing chondrocytes in lacunae 
nuclei are seen entrapped in the woven bone. They have moderate degree of uniform cellularity with small binuclear figures. The binucleated chondrocytes are seen in osteophytic spur of epiphyseal proliferative zone of normal laryngeal cartilage (Fig $3 \& 4$ ).

Surgical excision remains the treatment of choice. The lesions of anterior aspect of cricoid cartilage are better approached by thyrotomy whereas lessions of thyroid cartilage, post aspect of cricoid cartilage and arytenoid cartilage are approached by lateral external incision with or without pharyngotomy. According to Goethals et al. (1963) the incidence of recurrence is nil after complete removal of tumor through laryngofissure approach.

\section{References}

1. Contrell, W. W., Reibel, J. F., Johrscloerfer, R. A. and Johns, M. E., (1980): Conservative surgical treatment of chondrosarcoma of the larynx. Ann. Otol. Rhinol. Laryngol 89: 567.

2. Goethals, P. L., Dahlin, D. C. and Devine, K. D., (1963): Cartilagenous tumors of larynx. Surg. Gynec. Obstet. 117 : 77.82.

3. Huizenga, C. and Balogh, K. (1970): Cartilagenous tumors of larynx. A clinicopathologic study of 10 new cases and review of literature. Cancer $26: 201$.

4. Mills, S. E., Fechner, R. E., (1985): In pathology of the larynx. (An Atlas of Head \& Neck Pathology) Chicago. American Society of Clinical Pathologist Press.

5. Neel, H. B., Unni, K. K. (1982): Cartilagenous tumours of larynx. A series of 33 patients. Otolaryngol Head \& Neck Surg. $90: 201$.

6. Singh, J., Black, M. J., Fried, I. (1980): Cartilagenous tumours of larynx, A review of liteature and two cases experiences. Laryngoscope $90: 1872$.

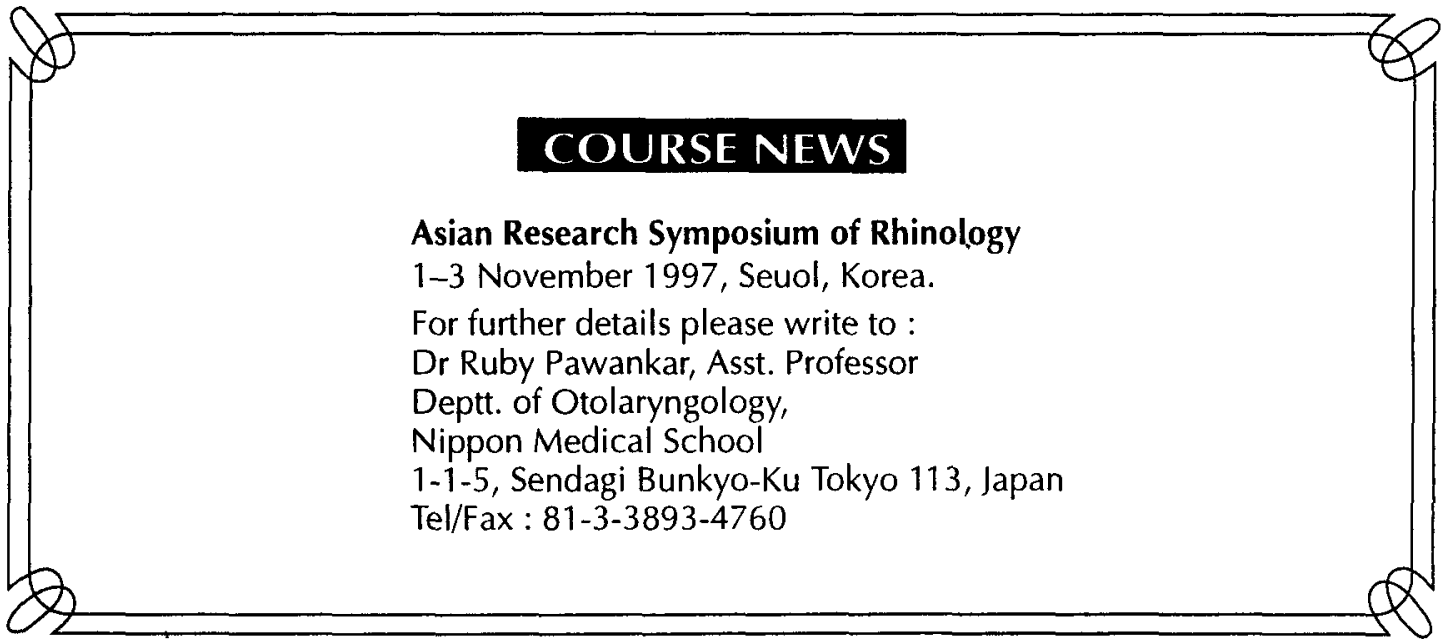

